\title{
Tropical Atlantic variability and coupled model climate biases: results from the Tropical Atlantic Climate Experiment (TACE)
}

\author{
W. E. Johns • P. Brandt • P. Chang
}

Published online: 31 October 2014

(C) Springer-Verlag Berlin Heidelberg 2014

Tropical Atlantic variability (TAV) and coupled model climate biases have been the focus of the recently completed Tropical Atlantic Climate Experiment (TACE, 2006-2011), an international CLIVAR program (http://www.clivar.org/ organization/atlantic/tace). TACE with its backbone, the Prediction and Research Moored Array in the Tropical Atlantic (PIRATA), was closely linked to other initiatives in the tropical Atlantic, such as the French EGEE (Etude de la circulation océanique et de sa variabilité dans le Golfe de Guinée) program and the African Monsoon Multidisciplinary Analyses (AMMA). One of the main goals of TACE was to improve the observational database in the equatorial Atlantic and to carry out dedicated process studies enhancing our understanding of the tropical Atlantic climate system. The regional focus of TACE was on the central and eastern equatorial Atlantic, characterized by the development of the Atlantic cold tongue (ACT) during boreal summer. The year-to-year variability of the ACT sea surface temperature

W. E. Johns $(\bowtie)$

Division of Meteorology and Physical Oceanography, Rosenstiel School of Marine and Atmospheric Science, University of Miami, 4600 Rickenbacker Causeway, Miami, FL 33149, USA

e-mail: bjohns@rsmas.miami.edu

P. Brandt

GEOMAR Helmholtz-Zentrum für Ozeanforschung Kiel,

Düsternbrooker Weg 20, 24105 Kiel, Germany

e-mail: pbrandt@geomar.de

P. Chang

Department of Oceanography, Texas A\&M University,

3146, College Station, TX 77840-3146, USA

e-mail:ping@tamu.edu

P. Chang

Department of Atmospheric Science, Texas A\&M University,

3146, College Station, TX 77840-3146, USA
(SST) has a strong influence on regional climate variations, including the strength and onset date of the West African Monsoon (WAM). However, the predictability of the WAM is strongly limited by large biases in coupled climate models. The observational studies presented here are largely based on enhanced observations taken during the TACE period, but also include studies based on historical and remote sensing data and data from the global in situ observing system. The enhanced observations have provided tremendous new insight into physical processes at work shaping the Atlantic climate system. However, while significant progress has been made towards improving coupled climate simulations of the tropical Atlantic, a strong bias in the southeastern tropical Atlantic is a common feature of current generation climate models. As this region still remains underrepresented in the available in situ observational datasets, new observational programs have been developed in the eastern tropical Atlantic, with a particular focus on the coastal upwelling regions. At the same time, the essential ocean observations obtained during TACE, including subsurface moorings along the equatorial wave guide, are being continued.

The articles contributed to this volume represent new advances in observing, modeling, understanding and predicting TAV. They encompass a range of topics, including tropical sea surface temperature, salinity, and subsurface oxygen variability, mixed layer heat and freshwater budgets, equatorial circulation and its seasonal to interannual variability, modes of tropical Atlantic variability, tropical Atlantic biases in coupled climate models and their potential causes, and connections between Atlantic and Pacific climate variability.

This special issue is coordinated by William Johns, Peter Brandt, and Ping Chang, representatives of the TACE Observations and TACE Modeling and Synthesis working groups. 